\title{
Association of 4-Repeat Allele of the Dopamine D4 Receptor Gene Exon III Polymorphism and Response to Methylphenidate Treatment in Korean ADHD Children
}

\author{
Keun-Ah Cheon', Boong-Nyun Kim*,2 and Soo-Churl Cho ${ }^{2}$ \\ 'Department of Psychiatry, Kwandong University College of Medicine, Kyunggi, South Korea; ${ }^{2}$ Division of Child and Adolescent Psychiatry, \\ Department of Psychiatry, Seoul National University, College of Medicine, Seoul, South Korea
}

\begin{abstract}
In the present study, we investigated the association between the 4-repeat allele at the dopamine receptor D4 (DRD4) gene and the response to treatment with methylphenidate $(\mathrm{MPH})$ in Korean children with attention deficit hyperactivity disorder (ADHD). The study subjects were 83 children with ADHD ( $8.40 \pm 1.73$ years) who were recruited from two child psychiatric clinics in South Korea. All of the drug-naive ADHD children were treated with MPH for about 8 weeks. An improvement of more than 50\% in the ADHD Rating Scale-IV (ARS) scores after 8 weeks of treatment compared with the baseline ARS scores before the treatment was considered as a 'good response', whereas an improvement of less than (or equal to?) 50\% was considered as a 'poor response'. After the genotyping for DRD4 was performed, we investigated the association between the genotype at DRD4 and the response to MPH treatment. We performed a comparison of the response to MPH treatment between the two largest groups, viz. the subjects with and without the 4/4 genotype at DRD4. According to the ARS scores of the subjects as assessed by their parents and by their teachers, we found that while 71.1 and 80.0\% (32/45 and 24/30), respectively, of those with a good response to MPH treatment showed the 4/4 genotype at DRD4, only 31.6 and 37.7\% (12/38 and 20/53), respectively, of those with a poor response to MPH treatment showed the 4/4 genotype at DRD4 (Pearson $\chi^{2}$-values $=12.926$ and 13.737, respectively, both $d f=1$, and both $p<0.01$ ). Our findings support the existence of an association between the 4-repeat allele at DRD4 and good response to MPH in Korean ADHD children.

Neuropsychopharmacology (2007) 32, I377- |383. doi: I0.1038/sj.npp. I 30 I244; published online I November 2006
\end{abstract}

Keywords: ADHD; 4-repeat allele; DRD4; methylphenidate; treatment response

\section{INTRODUCTION}

Attention deficit hyperactivity disorder (ADHD), which is characterized by inattention, hyperactivity, and impulsive behavior, is a condition which has various etiologies (Barkley, 1990). ADHD is frequent in school age children, $4-10 \%$ of whom are afflicted with this disorder, and causes long-term academic, social, emotional, and psychological problems (Hong and Oh, 1980; Szatmari et al, 1989; Cho and Shin, 1991). ADHD continues into adulthood in some cases and is a risk factor for antisocial behavior and drug abuse in ADHD children after they grow up (Mannuzza et al, 1993; Weiss and Hechtman, 1993). Many familial and

\footnotetext{
*Correspondence: Dr B-N Kim, Division of Child and Adolescent Psychiatry, Department of Psychiatry, Seoul National University, College of Medicine, 28, Yungun-Dong, Chonglo-Gu, Seoul, South Korea, Tel: 8222072 3647, Fax: 822747 5774,

E-mail: kbn I@snu.ac.kr

Received 3 August 2005; revised 21 July 2006; accepted 15 September 2006

Online publication: 26 September 2006 at http://www.acnp.org/ citations/Npp092606050473/default.pdf
}

genetic studies showed that the hereditary factor is important in the mechanism of ADHD development (Waldman et al, 1998; Faraone and Doyle, 2000).

Many candidate genes have been mentioned in relation to ADHD in several genetic studies. Methylphenidate (MPH), which is known to be effective for improving ADHD symptoms, operates through the mechanism of inhibiting the dopamine transporter (DAT) and is known to be effective for the attention deficient problems and impulsive behaviors of ADHD (Spencer et al, 1996). The results obtained from these studies suggest that the DAT gene (DAT1) is a potential risk factor for ADHD.

Separately, the dopamine receptor D4 (DRD4) gene has also been regarded as a leading candidate gene for ADHD. A study conducted in 1996 with 39 ADHD affected children and 39 normal children first reported the association between ADHD and DRD4 after finding the 7-repeat allele of the DRD4 exon III $48 \mathrm{bp}$ variable number of tandem repeats (VNTR) polymorphism (in the ADHD children? LaHoste et al, 1996). This finding was subsequently supported by other studies. Two studies proved that there was a greater transmission of the 7-repeat allele in ADHD 
children after analyzing a population of 52 nuclear families with the haplotype relative risk (HRR) method (Terwilliger and Ott, 1992; Swanson et al, 1998). Many studies have been conducted in an attempt to define the association of the DRD4 gene with ADHD (Castellanos et al, 1998; Rowe et al, 1998; Smalley et al, 1998; Faraone et al, 1999; Sunohara et al, 2000).

One of these studies asserted that there was no significant correlation between ADHD and the DRD4 polymorphism after comparing the frequency of the 7-repeat allele of DRD4 in children with acute ADHD and normal children. In a recent study using the transmission disequilibrium test (TDT), the frequency of transmission of the 7-repeat allele of DRD4 was found to be increased in families in which the children were afflicted with ADHD (Sunohara et al, 2000). Researchers have continued to attempt to prove the preferential transmission pattern of the 7-repeat allele of DRD4 exon III in relation to ADHD by using refined analysis techniques and different ethnic groups (Hawi et al, 2000; Sunohara et al, 2000).

At the same time, many studies have investigated the possible association between polymorphisms in genes involved in ADHD and the response to the medication treatment of ADHD. It is known that MPH, which improves ADHD symptoms by blocking DAT, is effective in $70 \%$ of ADHD children. However, research on the factors that could predict the degree of response to drug treatment is still in its infancy. Winsberg and Comings (1999) reported that the homozygosity of the 10-repeat allele at DAT1 was related to a poor response to $\mathrm{MPH}$ treatment in 30 African-American ADHD children. A double-blind study in 50 Brazilian ADHD boys also showed that the 10/10 genotype at DAT1 was significantly associated with the response to $\mathrm{MPH}$ treatment (Roman et al, 2002). Rohde et al (2003) recently reported that there was a difference in the regional cerebral blood flow (rCBF) measured with SPECT between the two groups, with and without homozygosity for the 10-repeat allele at DAT1, in eight ADHD boys who responded to MPH. In our previous study, we found a significant association between the homozygosity for the 10-repeat allele at DAT1 and the response to MPH treatment in Korean children with ADHD (Cheon et al, 2005).

The 7-repeat allele of a $48 \mathrm{bp}$ VNTR) in the exon-III of DRD4 was identified as a risk allele and has been investigated in various association studies, with both positive and negative results. In addition, the presence of the 7-repeat allele of the DRD4 gene seems to be associated with a poor response to MPH treatment in ADHD (Seeger et al, 2001). Hamarman et al (2004) reported that ADHD children possessing the DRD4 7-repeat allele require higher doses of MPH for symptom improvement and symptom normalization, and suggested the possibility that the 7repeat allele of the DRD4 gene VNTR polymorphism correlates with treatment outcome. This 7-repeat allele, however, is rarely present in Asian populations, such as Chinese, Japanese, and Korean children (Lichter et al, 1993). Many previous studies have reported that the most frequent allele and genotype of DRD4 in the Korean population were the 4-repeat allele and 4/4, respectively (Lee et al, 2003a, b). In addition, the common 4-repeat allele has been identified as the conserved ancestral allele (Ding et al, 2002; Wang et al, 2004). Furthermore, the available biochemical data indicate that the 4-repeat protein has a significantly less blunted response to dopamine than the 2-repeat and 7repeat proteins (Asghari et al, 1995). One preliminary report suggested that $\mathrm{ADHD}$ children having the 7-repeat allele but not having a 4-repeat allele of the DRD4 exon-III VNTR polymorphism showed a worse response to treatment with MPH than ADHD children having the 4-repeat allele, owing to the decreased function of the D4 receptor (Sallee, 2004). It was particularly suggested that the 4-repeat allele at DRD4 could be a predictor of the response to treatment with both MPH and atomoxetine.

We hypothesized that the 4-repeat allele at the DRD4 gene might be associated with a better response of ADHD children to treatment with MPH. Thus, in the present study, we investigated the association between the genotype at the DRD4 gene and the response to MPH treatment in Korean children with ADHD.

\section{MATERIALS AND METHODS}

\section{Subjects}

The present study comprised 83 ADHD children $(8.23 \pm 1.78$ years) who were recruited from two child psychiatric clinics in South Korea. The children selected for the ADHD group were those children (1) who were diagnosed as having ADHD combined type according to the DSM-IV Diagnostic Criteria of Mental Disorders, (2) who were aged 7-12 years, (3) who and whose parents/guardians agreed to participate in the study, with provision of informed consent before inclusion, (4) who were never exposed to psychostimulants such as MPH. We excluded those children (1) with tic symptoms, obsessive compulsive symptoms or any other mental disorders, (2) who had a past history or were currently suffering from brain damage or convulsive disorder, (3) who were mentally handicapped or had autism, language difficulties, or developmental problems including learning disability, (4) who or whose parents/ guardians did not agree to the study.

This study was approved by the institutional review boards for human subjects at the University of Yonsei, Yongdong Severance Hospital, and Seoul National University hospital in Seoul, Korea.

\section{Diagnostic and Evaluation Tools of Clinical Symptoms}

(1) Kiddie-Schedule for Affective Disorders and Schizophrenia-Present and Lifetime Version (K-SADS-PL) (Kaufman et al, 1997): the Korean version of K-SADSPL was translated by Kim et al (2004) and its validity and reliability for the evaluation of ADHD, tic disorder, and oppositional defiant disorder were previously validated.

(2) ADHD Rating Scale-IV (ARS): composed of a total of 18 items, ARS is the ADHD symptom severity scale designed by DuPaul et al (1998) according to the DSM-IV Diagnostic Criteria of Mental Disorders. Each item has a 4-point scale ranging from 0 to 3 . The 18 items are composed of nine items reflecting the symptoms related to inattention and nine items reflecting the symptoms related to hyperactivity and 
impulsivity. Either the parents or teacher can complete the scale for the ADHD child and both scales have the same items. The Korean version of ARS was standardized by So et al (2002).

\section{MPH Administration and Treatment Response}

All of the ADHD subjects were administered MPH for 8 weeks. The dosages were increased up to a sufficient dose to achieve the therapeutic effect, based on the parents' reports of symptom improvement and side effects. Then, these dosage levels were maintained for 8 weeks. The ARS scores were assessed by the parents and teachers before and after the 8-week course of MPH treatment, in order to assess the improvement of the ADHD symptoms.

An improvement in the ARS score after 8 weeks of treatment of more than $50 \%$ compared with the baseline ARS score before the treatment was considered a 'good response', whereas an improvement of less than $50 \%$ was considered a 'poor response'. All of the procedures were performed by medical staff who were blinded to the results of the DRD4 genotyping.

\section{Preparation of Genomic DNA}

Genomic DNA was extracted from blood lymphocytes using a Genomic DNA Extraction kit (Bioneer, Korea).

\section{DRD4-Exon3 Genotype Determination}

The DRD4-exon III repeat region was genotyped by a PCRbased length polymorphism (test/method?).

The oligonucleotide primers $\left(5^{\prime}\right.$-ACCACCACCGGCAG GACCCTCATGGCCTTGCGCTC- ${ }^{\prime}$ and $5^{\prime}$-CTTCCTACCCT GCCCGCTCATGCTGCTGCTCTACTGG-3') were used to generate the DRD4-exon III polymorphic region (2-10 variable repeat units, 1 unit $=48 \mathrm{bp}$ ). PCR amplification was performed with a volume of $20 \mu \mathrm{l}$ containing $100 \mathrm{ng}$ of genomic DNA, 10 pmol of each primer, $1 \times$ PFU PCR buffer (Solgent, Korea), $400 \mu \mathrm{M}$ dATP, dTTP and dCTP, $200 \mu \mathrm{M}$ dGTP (Solgent, Korea), $200 \mu \mathrm{M}$ 7-Deaza-dGTP (Boehringer Mannheim), 5\% DMSO, and $2 \mathrm{U}$ Solgent PFU Taq. The reaction consisted of a denaturation step at $98^{\circ} \mathrm{C}$ for $5 \mathrm{~min}$, followed by 35 cycles consisting of $98^{\circ} \mathrm{C}$ for $45 \mathrm{~s}, 55^{\circ} \mathrm{C}$ for $45 \mathrm{~s}$, and $72^{\circ} \mathrm{C}$ for $1 \mathrm{~min} 30 \mathrm{~s}$, with a final extension step at $72^{\circ} \mathrm{C}$ for $5 \mathrm{~min}$. Thermal cycling was performed on an MJ

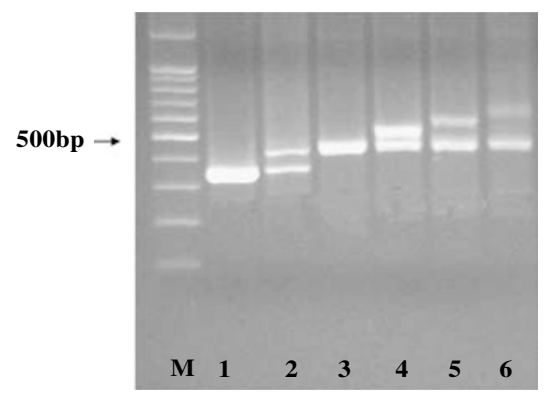

$$
\begin{aligned}
& \text { M : } 100 \text { bp size Marker } \\
& \text { 1: } 2 / 2 \text { repeat type } \\
& \text { 2: } 2 / 4 \text { repeat type } \\
& \text { 3: } 4 / 4 \text { repeat type } \\
& \text { 4: } 4 / 5 \text { repeat type } \\
& \text { 5: } 4 / 6 \text { repeat type } \\
& \text { 6: } 4 / 7 \text { repeat type }
\end{aligned}
$$

Figure I PCR analysis of exon III 48 bp VNTR of the dopamine receptor 4 gene (DRD4). research PTC-100 thermal cycler. The amplification products were electrophoresed on a $2 \%$ agarose gel and visualized by EtBR staining (Kotler et al, 2000) (Figure 1).

\section{Statistical Analysis}

The correlation between the genotype at DRD4 and the response to MPH treatment was evaluated using the $\chi^{2}$ (Chisquare) test. The level of significance was $5 \%$ (two-tailed).

\section{RESULTS}

\section{Demographic and Clinical Characteristics}

The 83 ADHD children (mean age $=8.40 \pm 1.73$ years) comprised 72 boys (mean age $=8.35 \pm 1.77$ years) and 11 girls (mean age $=8.73 \pm 1.49$ years). The average IQ of the ADHD subjects was $111.87 \pm 17.46$. The average scores of the overall symptoms of ADHD according to the ARS, as measured by the parents and teachers of the ADHD children, decreased from $34.41 \pm 8.16$ to $30.33 \pm 8.19$, respectively, at baseline between $17.95 \pm 5.20$ and $17.98 \pm 4.43$, respectively, after 8 weeks of MPH treatment (Table 1 ).

\section{Genetic Polymorphisms of DRD4}

Among the 83 ADHD children, the 4-repeat allele of the 48bp VNTR polymorphism at DRD4 was identified in 123 of the 166 chromosomes $(74.1 \%)$ and the 2-repeat allele was identified in 30 of the 166 chromosomes (18.1\%). The 5repeat, 6-repeat, and 7-repeat alleles were identified in 5, 3, and 1 of the 166 chromosomes, respectively $(3.0,1.8$, and $0.0 \%)$. The distribution of the genotypes for the DRD4 exon-III VNTR was in agreement with the expected values of the Hardy-Weinberg equilibrium (goodness of fit $\chi^{2}$ value $=1.13, \mathrm{df}=5, p=0.89$ ). To perform the quality control of the genotyping method used in this study, we selected 10 samples randomly and reanalyzed them in a blind manner. No discrepancies were found. The $4 / 4$

Table I Clinical Characteristics of the ADHD Subjects $(N=83)$

\begin{tabular}{lr}
\hline Characteristics & Number (\%) \\
\hline Sex & $72(86.8)$ \\
Male & $11(15.5)$ \\
Female & Mean \pm SD \\
& $8.40 \pm 1.77$ \\
Age (years) & \\
& \\
IQ & $111.87 \pm 17.46$ \\
Total IQ & $112.13 \pm 18.18$ \\
Verbal IQ & $108.61 \pm 16.10$ \\
Performance IQ & \\
CDI & $20.86 \pm 6.89$
\end{tabular}

SD: standard deviation; CDI: childhood depression inventory. 
genotype was observed in 44 ADHD children (53.0\%), the $4 / 2$ genotype in $30(36.1 \%)$, the $4 / 5$ genotype in five $(6.0 \%)$, the $4 / 6$ genotype in three $(3.6 \%)$, and the $4 / 7$ genotype in only one $(1.2 \%)$.

Table 2 Correlation between the Genotype at DRD4 and the Response of the ADHD Children to the Treatment with Methylphenidate According to the ARS, as Assessed by their Parents and Teachers ${ }^{\mathrm{a}}$

\begin{tabular}{|c|c|c|c|c|c|}
\hline & \multirow[b]{2}{*}{ Genotype } & & \multicolumn{2}{|c|}{$\begin{array}{c}\text { Response to } \mathrm{MPH} \\
\text { treatment } N \text { (\% within } \\
\text { response) }\end{array}$} & \multirow[b]{2}{*}{ Total } \\
\hline & & & $\begin{array}{c}\text { Poor } \\
(<\mathbf{5 0 \% )}\end{array}$ & $\begin{array}{c}\text { Good } \\
(\geqslant \mathbf{5 0} \%)\end{array}$ & \\
\hline \multirow{10}{*}{$\begin{array}{l}\text { ADHD } \\
\text { children }\end{array}$} & $4 / 4$ & Parent $^{\mathrm{a}}$ & $12(31.6 \%)$ & 32 (7I.1\%) & 44 \\
\hline & & Teacher $^{b}$ & 20 (37.7\%) & $24(80.0 \%)$ & \\
\hline & $4 / 2$ & Parent $\mathrm{a}^{\mathrm{a}}$ & $20(52.6 \%)$ & $10(22.2 \%)$ & 30 \\
\hline & & Teacher ${ }^{b}$ & $25(47.2 \%)$ & $5(54.5 \%)$ & \\
\hline & $4 / 5$ & Parent $\mathrm{a}^{\mathrm{a}}$ & 3 (7.9\%) & $2(4.4 \%)$ & 5 \\
\hline & & Teacher $^{b}$ & $4(7.5 \%)$ & | (3.3\%) & \\
\hline & $4 / 6$ & Parent ${ }^{\mathrm{a}}$ & $2(5.3 \%)$ & | (2.2\%) & 3 \\
\hline & & Teacher $^{b}$ & $3(5.7 \%)$ & $0(0 \%)$ & \\
\hline & $4 / 7$ & Parent $\mathrm{a}^{\mathrm{a}}$ & I (2.6\%) & $0(0 \%)$ & I \\
\hline & & Teacher $^{b}$ & I (1.9\%) & $0(0 \%)$ & \\
\hline \multirow[t]{2}{*}{ Total } & & Parent $^{\mathrm{a}}$ & 38 & 45 & 83 \\
\hline & & Teacher $^{b}$ & 53 & 30 & \\
\hline
\end{tabular}

The $\chi^{2}$-test (by Fisher's Exact test) was used for correlation.

aPearson $\chi^{2}$-value $=13.463, \mathrm{df}=4, p<0.01$.

bearson $\chi^{2}$-value $=14.215, \mathrm{df}=4, p<0.01$ (by Fisher's Exact test).

Parent: according to ARS assessed by parent; teacher: according to ARS

assessed by teacher; $\mathrm{MPH}$ : methylphenidate.

\section{Correlation between the Genotype at DRD4 and the Response to MPH Treatment}

According to the ARS scores of the children as assessed by their parents and by their teachers, we found that 71.7 and $80.0 \%$ (32/44 and 24/30), respectively, of the subjects with the $4 / 4$ genotype at DRD4 showed a good response ( $>50 \%$ improvement) to MPH treatment. However, only 22.2 and $16.7 \%$ (10/45 and 5/30), respectively, of the subjects with the $4 / 2$ genotype at DRD4 showed a good response to MPH treatment, and only 4.4 and $3.3 \%(2 / 45$ and $1 / 30)$ of the subjects with the $4 / 5$ genotype showed a good response to MPH treatment. None of the subjects with the $4 / 6$ or $4 / 7$ genotype showed a good response to MPH treatment (Pearson $\chi^{2}$-value $=13.463$ and 14.215 , respectively, both $\mathrm{df}=4$, and both $p<0.01$ ) (Table 2 ).

\section{Comparison of the Response to MPH Treatment between the Subjects with and without the 4/4 Genotype at DRD4}

We performed a comparison of the response to MPH treatment between the two largest groups, viz. the subjects with and without the 4/4 genotype at DRD4. We found that the response to MPH treatment, as assessed by the parents and teachers, was significantly associated with the presence of the $4 / 4$ genotype at DRD4 (Pearson $\chi^{2}$-value $=12.926$ and 13.737, both $\mathrm{df}=1$, and both $p<0.01$ ) (Table 3 ).

No significant differences in the mean age or baseline ARS scores of the ADHD children, as assessed by their parents, were found between those with and without the 4/4 genotype of DRD4. Those ADHD children with the 4/4 genotype of DRD4 had a significantly higher score in the total scales of ARS, as assessed by their teachers, than those children without the $4 / 4$ genotype of DRD4 (Table 3). We found no significant differences in the average daily dose of MPH between the ADHD children with and without the 4/4 genotype, or between the two largest genotype groups (the subjects with the $4 / 4$ genotype and the $4 / 2$ genotype) (Table 4 ).

Table 3 Correlation between the 4/4 Genotype at DRD4 and the Response of the ADHD Children to the Treatment with Methylphenidate According to the ARS, as Assessed by Their Parents and Teachers ${ }^{\mathrm{a}}$

\begin{tabular}{|c|c|c|c|c|c|c|c|}
\hline & & & \multicolumn{2}{|c|}{$\begin{array}{l}\text { Mean total ARS score } \\
\quad(\text { mean } \pm \text { SD) }\end{array}$} & \multicolumn{2}{|c|}{$\begin{array}{c}\text { Response to MPH treatment } \mathbf{N} \\
\text { (\% within response) }\end{array}$} & \multirow[b]{2}{*}{ Total } \\
\hline & & & Baseline & Post-MPH & Poor & Good & \\
\hline \multirow[t]{3}{*}{ ADHD children } & With $4 / 4$ genotype & Parent $^{\mathrm{a}}$ & $35.70 \pm 7.97$ & $|6.9| \pm 4.23$ & $12(31.6 \%)$ & 32 (7I.1\%) & 44 \\
\hline & & Teacher $^{b}$ & $32.02 \pm 8.37$ & $17.52 \pm 4.04$ & 20 (37.7\%) & 24 (80.0\%) & \\
\hline & Without $4 / 4$ genotype & Parent $^{\mathrm{a}}$ & $32.95 \pm 8.23 *$ & $19.13 \pm 5.94$ & $26(68.4 \%)$ & $13(28.9 \%)$ & 39 \\
\hline \multirow[t]{2}{*}{ Total } & & Parent $^{\mathrm{a}}$ & $34.41 \pm 8.16$ & $17.95 \pm 5.20$ & 38 & 45 & 83 \\
\hline & & Teacher $^{b}$ & $30.33 \pm 8.19$ & $17.98 \pm 4.43$ & 53 & 30 & \\
\hline
\end{tabular}

The $\chi^{2}$-test (by Fisher's Exact test) was used for correlation, Parent: according to ARS assessed by parent; teacher: according to ARS assessed by teacher.

apearson $\chi^{2}$-value $=12.926, \mathrm{df}=1, p<0.01$.

${ }^{\mathrm{b}}$ Pearson $\chi^{2}$-value $=13.737, \mathrm{df}=1, p<0.01$ (by Fisher's Exact test).

*p $<0.05$ (by Student t-test); MPH: methylphenidate. 
Table 4 Comparison of the Dosage of MPH Per Day between the ADHD Children with and without the 4/4 Genotype and between Those with the 4/4 and 4/2 Genotypes at DRD4

MPH dose (mg/day) mean \pm SD

\begin{tabular}{lccc}
\cline { 2 - 3 } & Final dose & Average dose & p-value \\
\hline With 4/4 $(N=44)$ & $24.91 \pm 7.12$ & $21.08 \pm 5.67$ & 0.669 \\
W/O 4/4 $(N=39)$ & $24.21 \pm 7.81$ & $20.21 \pm 4.76$ & 0.452 \\
With 4/4 $(N=44)$ & $24.91 \pm 7.12$ & $21.08 \pm 5.67$ & 0.619 \\
With 4/2 $(N=31)$ & $24.06 \pm 7.36$ & $19.92 \pm 4.25$ & 0.338 \\
& & & \\
Total subjects $(N=83)$ & $24.58 \pm 7.41$ & $20.67 \pm 7.25$ &
\end{tabular}

SD: standard deviation, with 4/4: ADHD children with homozygosity for the 4-repeat allele at DRD4, W/O 4/4: ADHD children without homozygosity for the 4-repeat allele at DRD4, with 4/2: ADHD children with the 4/2 genotype at DRD4.

We found a proportionate distribution of males and females in the two genotype or treatment response groups. The numbers of males and females with the $4 / 4$ genotype at DRD4 were $38(52.8 \%)$ out of 72 and five $(54.5 \%)$ out of 11 , respectively. No significant difference in the gender distribution was found between the two genotype groups (Pearson $\chi^{2}$-value $=0.012, \mathrm{df}=1$, and $p=0.913$ ). We found that the numbers of ADHD children who were considered by their parents to exhibit a good response to treatment were $39(54.2 \%)$ out of 72 males and six $(54.5 \%)$ out of 11 females (Pearson $\chi^{2}$-value $=0.001, \mathrm{df}=1$, and $p=0.981$ ), and the numbers of ADHD children who were considered by their teachers to exhibit a good response to treatment were $24(33.3 \%)$ out of 72 males and $6(54.5 \%)$ out of 11 females (Pearson $\chi^{2}$-value $=1.860, \mathrm{df}=1$, and $p=1.173$ ). No significant difference in the gender distribution was found between the good and poor treatment response groups.

\section{DISCUSSION}

This study identified a significant association between the DRD4 exon III 48-bp VNTR polymorphism and the response to MPH treatment in ADHD children. Those subjects homozygous for the 4-repeat allele at DRD4 showed a better response to MPH treatment than those who were not homozygous for this allele. These findings are relatively consistent with the preliminary results of the 2004 Sallee study. In addition, the findings of the present study are important, because it was conducted with only Korean ADHD children.

There have been few studies that defined the association of ADHD and the 4-repeat allele of DRD4. Barr et al (2000) conducted a TDT analysis to determine the association between ADHD and DRD4 and found significant evidence for the biased transmission of the 7-repeat allele and nontransmission of the 4-repeat allele. They interpreted this interesting finding of the nontransmission of the 4-repeat allele as compensation for the excess transmission of the 7-repeat allele, thereby signaling the possibility that the 4-repeat allele might be a protective factor in reducing the risk of developing ADHD. These findings are in agreement with those of other recent studies (Ding et al, 2002; Wang et al, 2004; Asghari et al, 1995) and are supported by the findings of the present study.

Recently, researchers have stepped up their efforts to estimate the treatment outcomes for mental illness by investigating the effects of pharmacogenetics. Roses (2001) predicted the completion of SNP profiles in patients who showed a clinically positive response to medication treatment for psychiatric disorders. However, little pharmacogenetic research has been conducted into the treatment of children with psychiatric disorders such as ADHD. Even though there have been a few pharmacogenetic studies dealing with children, their sample sizes tended to be too small (Anderson and Cook, 2000). The present study marked an important milestone in genetic approaches to increasing the understanding of the mechanism behind ADHD symptoms in children, since it used a larger sample size than previous studies investigating the association of DRD4 with ADHD. The existing studies, which were mainly conducted with Europeans or Caucasians, reported poor treatment outcomes in the presence of the 7-repeat allele of the DRD4 VNTR polymorphism (Seeger et al, 2001; Hamarman et al, 2004; Sallee, 2004). However, the 7-repeat allele of the DRD4 exon III VNTR polymorphism has not been found in studies conducted with Asian people, including the present study and, consequently, it is difficult to verify the research findings obtained from white ADHD children in Asian ADHD children. Whereas there was a preliminary study suggesting the possible involvement of the 4-repeat allele in ADHD treatment (Sallee, 2004), the present study provided evidence that the same allele had beneficial effects in the treatment of Korean ADHD children, and has therefore significantly advanced the state of research in this promising treatment field.

Recently, Leung et al (2005) reported a significantly increased prevalence of the 2-repeat allele at DRD4 in Han Chinese ADHD children, whereas none of them had the DRD4 7-repeat allele. In this context, it should be noted that a biochemical analysis conducted in a previous study demonstrated that the 7-repeat protein has a threefold reduced ability to reduce cAMP levels, as compared to the 4 -repeat protein. In this same study, the 2-repeat protein also exhibited an inhibited cAMP response, which was midway between those of the 4-repeat and 7-repeat variants (Asghari et al, 1995). The resequencing analysis conducted by Wang et al (2004) showed unequivocally that the 2repeat allele in Asians is a recombination product of the 7-repeat allele. The present study also identified the presence of the 2-repeat allele in $78.1 \%$ of the subjects not homozygous for the 4-repeat allele at DRD4, which was statistically significant $(p<0.01)$. It is likely that the 2-repeat allele at DRD4 was related to the poor outcome of MPH treatment. Further studies with larger sample sizes are therefore needed to confirm the association of the 2-repeat allele with ADHD or poor treatment outcomes in ADHD children.

This study had some limitations. First, other sociopsychological factors that might have influenced the outcome of the MPH treatment in the ADHD subjects were not excluded. In the selection of the subjects, the authors 
tried to minimize the variables affecting the treatment outcome by excluding children with mental disorders concomitant to ADHD. More studies need to be conducted with more precise control of the variables that may affect the treatment outcome in ADHD children. Secondly, those subjects homozygous for the 4-repeat allele at DRD4 showed a higher ARS score at baseline, as measured by the teachers, than those subjects who were not homozygous for this allele. This means that a big change in the ARS score between baseline and after treatment might have been interpreted as a good outcome in those subjects homozygous for the 4-repeat allele, as demonstrated in the teachers' assessment. Despite the possibility that those subjects homozygous for the 4-repeat allele might have shown a poor response to MPH treatment due to their more severe symptoms, the ARS score in this group significantly improved, thus supporting the finding of a good outcome in the group homozygous to the 4-repeat allele. Thirdly, in this study, the subjects were divided into two groups according to the presence or absence of the 4-repeat allele of the DRD4 exon III VNTR polymorphism, without considering the number of 4-repeat alleles. The analysis of the treatment outcomes corresponding to the absence of or presence of one or two 4-repeat alleles would provide more specific evidence for the relationship between the 4-repeat allele at DRD4 and ADHD. As only three of the 39 subjects (7.7\%) with the heterozygous genotype of DRD4 did not have any 4-repeat alleles, however, it was not statistically meaningful to form a separate group. The association between the change in the treatment outcome and the number of 4 repeat alleles needs to be further investigated with a larger sample size.

Despite these limitations, this study is the first of its kind in the area of pharmacogenetics to design a treatment plan for the management of ADHD in an Asian population. To use the functions of the DRD4 gene as a predictor for treatment outcome in patients with ADHD, further studies with larger sample sizes need to be conducted in various Asian ethnic groups.

\section{REFERENCES}

Anderson GM, Cook EH (2000). Pharmacogenetics: promise and potential in child and adolescent psychiatry. Child Adolesc Psychiatry Clin N Am 9: 23-42.

Asghari V, Sanyal S, Buchwaldt S, Paterson A, Jovanovic V, Van Tol HH (1995). Modulation of intracellular cyclic AMP levels by different human dopamine D4 receptor variants. J Neurochem 65: 1157-1165.

Barkley RA (1990). Critique of current diagnostic criteria for attention deficit hyperactivity disorder: clinical and research implications. J Dev Behav Pediatr 11: 343-352.

Barr CL, Wigg KG, Bloom S, Schachar R, Tannock R, Roberts W et al (2000). Further evidence from haplotype analysis for linkage of the dopamine D4 receptor gene and attention-deficit hyperactivity disorder. Am J Med Genet 96: 262-267.

Castellanos FX, Lau E, Tayebi N, Lee P, Long RE, Giedd JN et al (1998). Lack of association between a dopamine-4 receptor polymorphism and attention-deficit/hyperactivity disorder: genetic and brain morphometric analyses. Mol Psychiatry 3: 431-434.

Cheon KA, Ryu YH, Kim JW, Cho DY (2005). The homozygosity for 10-repeat allele at dopamine transporter gene and dopamine transporter density in Korean children with attention deficit hyperactivity disorder: relating to treatment response to methylphenidate. Eur Neuropsychopharmacol 15: 95-101.

Cho SC, Shin YO (1991). The prevalence of disruptive behavior disorders. Kor J Child Adolesc Psychiatry 41: 141-149.

Ding YC, Chi HC, Grady DL, Morishima A, Kidd JR, Kidd KK et al (2002). Evidence of positive selection acting at the human dopamine receptor D4 gene locus. Proc Natl Acad Sci USA 99: 309-314.

DuPaul GJ, Power TJ, Anastopoulos AD, Reid R (1998). ADHD Rating Scale-IV: Checklists, Norms, and Clinical Interpretation. Guilford Press: New York.

Faraone SV, Beiderman J, Weiffenbach B, Keith T, Chu MP, Weaver A et al (1999). Dopamine D4 gene 7-repeat allele and attention deficit hyperactivity disorder. Am J Psychiatry 156: 768-770.

Faraone SV, Doyle AE (2000). Genetic influences on attention deficit hyperactivity disorder. Curr Psychiatry Rep 2: 143-146.

Hamarman S, Fossella J, Ulger C, Brimacombe M, Dermody J (2004). Dopamine receptor 4 (DRD4) 7-repeat allele predicts methylphenidate dose response in children with attention deficit hyperactivity disorder: a pharmacogenetic study. J Child Adolesc Psychopharmacol 14: 564-574.

Hawi Z, McCarron M, Kirley A, Daly G, Fitzgerald M, Gill M (2000). No association of the dopamine DRD4 receptor (DRD4) gene polymorphism with attention deficit hyperactivity disorder (ADHD) in the Irish population. Am J Med Genet 96: 268-272.

Hong KE, Oh KJ (1980). Patients with symptoms of hyperactivity visiting child psychiatry and pediatrics clinic. Kor J Update Psychiatry 23: 51-57.

Kaufman J, Birmaher B, Brent D, Rao U, Flynn C, Moreci P et al (1997). Schedule for affective disorders and schizophrenia for school-age children-present and life time version (K-SADS-PL): initial reliability and validity data. $J$ Am Acad Child Adolesc Psychiatry 36: 980-988.

Kim YS, Cheon KA, Kim BN, Chang SA, Yoo HJ, Kim JW et al (2004). The reliability and validity of Kiddie-Schedule for Affective Disorders and Schizophrenia-Present and Lifetime Version-Korean version (K-SADS-PL-K). Yonsei Med J 45: 81-89.

Kotler M, Manor I, Sever Y, Eisenberg J, Cohen H, Ebstein RP et al (2000). Failure to replicate an excess of the long dopamine D4 exon III repeat polymorphism in ADHD in a family-based study. Am J Med Genet 96: 278-281.

LaHoste GJ, Swanson JM, Wigal SB, Glabe C, Wigal T, King N et al (1996). Dopamine D4 receptor gene polymorphism is associated with attention deficit hyperactivity disorder. Mol Psychiatry 1: 121-124.

Lee HJ, Lee HS, Kim YK, Kim L, Lee MS, Jung IK et al (2003a). D2 and D4 dopamine receptor gene polymorphisms and personality traits in a young Korean population. Am J Med Genet B Neuropsychiatr Genet 121: 44-49.

Lee HJ, Lee HS, Kim YK, Kim SH, Kim L, Lee MS et al (2003b). Allelic variants interaction of dopamine receptor D4 polymorphism correlate with personality traits in young Korean female population. Am J Med Genet B Neuropsychiatr Genet 118: 76-80.

Leung PW, Lee CC, Hung SF, Ho TP, Tang CP, Kwong SL et al (2005). Dopamine receptor D4 (DRD4) gene in Han Chinese children with attention-deficit/hyperactivity disorder (ADHD): increased prevalence of the 2-repeat allele. Am J Med Genet $B$ Neuropsychiatr Genet 133: 54-56.

Lichter JB, Barr CL, Kennedy JL, Van Tol HH, Kidd KK, Livak KJ (1993). A hypervariable segment in the human dopamine receptor D4 (DRD4) gene. Hum Mol Genet 2: 767-773.

Mannuzza S, Klein RG, Bessler A, Malloy P, LaPadula M (1993). Adult outcome of hyperactive boys. Educational achievement, occupational rank, and psychiatric status. Arch Gen Psychiatry 50: $565-576$. 
Rohde LA, Roman T, Szobot C, Cunha RD, Hutz MH, Biederman J (2003). Dopamine transporter gene, response to methylphenidate and cerebral blood flow in attention-deficit/hyperactivity disorder: a pilot study. Synapse 48: 87-89.

Roman T, Szobot C, Martins S, Biederman J, Rohde LA, Hutz MH (2002). Dopamine transporter gene and response to methylphenidate in attention-deficit/hyperactivity disorder. Pharmacogenetics 12: 497-499.

Roses AD (2001). Pharmacogenetics. Hum Mol Genet 10: 2261-2267.

Rowe DC, Stever C, Cleveland HH, Standers ML, Abramowitz A, Kozel ST et al (1998). The relation of the dopamine transporter gene (DAT1) to symptoms of internalizing disorders in children. Behav Genet 28: 215-225.

Sallee FR (2004). Pharmacogenetics of atomoxetine: relevance of DRD4. Scientific Proceedings of the 51st annual meeting of American Academy of Child and Adolescent Psychiatry. Washington, DC. 28pp.

Seeger G, Schloss P, Schmidt MH (2001). Marker gene polymorphism in hyperkinetic disorder-predictors of clinical response to treatment with methylphenidate? Neurosci Lett 313: 45-48.

Smalley SL, Bailey JN, Palmer CG, Cantwell DP, McGough JJ, Del'Homme MA et al (1998). Evidence that the dopamine D4 receptor is a susceptibility gene in attention deficit hyperactivity disorder. Mol Psychiatry 3: 427-430.

So YK, Noh JS, Kim YS, Ko SG, Koh YJ (2002). The reliability and validity of Korean parent and teacher ADHD rating scale. J Kor Neuropsychiatr Assoc 41: 283-289.

Spencer T, Biederman J, Wilens T, Harding M, O'Donnell D, Griffin SJ (1996). Pharmacotherapy of attention-deficit hyperactivity disorder across the life cycle. J Am Acad Child Adolesc Psychiatry 35: 409-432.
Sunohara GA, Roberts W, Malone M, Schachar RJ, Tannock R, Basile VS et al (2000). Linkage of the dopamine D4 receptor gene and attention-deficit/hyperactivity disorder. J Am Acad Child Adolesc Psychiatry 39: 1537-1542.

Swanson JM, Sunohara GA, Kennedy JL, Regino R, Fineberg E, Wigal $\mathrm{T}$ et al (1998). Association of the dopamine receptor D4(DRD4) gene with a refined phenotype of attention deficit hyperactivity disorder: a family-based approach. Mol Psychiatry 3: $370-372$.

Szatmari P, Offord DR, Boyle MH (1989). Correlates, associated impairments and patterns of service utilization of children with attention deficit disorder: findings from the Ontario Child Health Study. J Child Psychol Psychiatry 30: 205-217.

Terwilliger J, Ott J (1992). A haplotype-based haplotype relative risk approach to detecting allelic association. Hum Hered 42: 337-346.

Waldman ID, Rowe DC, Abramowitz A, Kozel ST, Mohr JH, Sherman SL et al (1998). Association and linkage of the dopamine transporter gene and attention-deficit hyperactivity disorder in children: heterogeneity owing to diagnostic subtype and severity. Am J Hum Genet 63: 1767-1776.

Wang E, Ding YC, Flodman P, Kidd JR, Kidd KK, Grady DL et al (2004). The genetic architecture of selection at the human dopamine receptor D4 (DRD4) gene locus. Am J Hum Genet 74: 931-944.

Weiss G, Hechtman L (1993). Hyperactive Children Grow Up: Empirical Findings and Theoretical Considerations, 2nd edn. Guilford Press: New York.

Winsberg BG, Comings DE (1999). Association of the dopamine transporter gene (DAT1) with poor methylphenidate response. J Am Acad Child Adolesc Psychiatry 38: 1474-1477. 